\title{
PENGARUH PRODUK, KUALITAS PELAYANAN TERHADAP CITRA PERUSAHAAN YANG BERDAMPAK TERHADAP KEPUASAN NASABAH PADA PT BANK OCBC NISP, TBK CABANG GREEN GARDEN
}

\author{
Mita Sicillia \\ Email:dosen02191@gmail.com
}

\begin{abstract}
ABSTRAK
Setiap perusahaan berusaha mendapatkan pelangggan baru dan mempertahankan pelanggan lama yang telah eksis, keberhasilan perusahaan tersebut tidak lepas dengan adanya kepuasan pelanggan terhadap perusahaan. Adanya kondisi tersebut menuntut agar pihak perusahaan berusaha melakukan pengukuran kepuasan pelanggan dengan cara menganalisa faktor dari dari nilai produk yang dimiliki, kualitas pelayanan yang diberikan kepada pelanggan dan citra perusahaan di mata pelanggan, sehingga sebuah perusahaan dapat menjaga bahkan meningkatkan kepuasan para pelanggannya.

Penelitian ini bertujuan untuk mengetahui Pengaruh Produk, Kualitas Pelayanan tehadap Citra Perusahaan serta dampaknya terhadap kepuasan nasabah PT Bank OCBC NISP, Tbk. Cabang Green Garden . Populasi dalam penelitian ini adalah semua nasabah pada PT bank OCBC NISP, Tbk Cabang Green Garden yang berjumlah 100 orang, sehingga penelitian ini meupakan penelitian sensus. Alat analisis yang digunakan dalam penelitian ini adalah regresi sederhana, regresi linier berganda.

Dari pengujian yang dilakukan terdapat pengaruh nilai produk, kualitas pelayanan dan citra perusahaan secara bersama-sama terhadap kepuasan nasabah secara statistik menunjukkan hasil yang positif dan signifikan. Hal ini ditunjukkan oleh nilai $F$ hitung sebesar 86.251 dengan $F$ tabel adalah 2.699. Besarnya nilai $F$ hitung $>F$ tabel mengindikasikan bahwa pengaruhnya berdampak positif dan signifikan. Dengan demikian telah terbukti bahwa Produk, Kualitas Pelayanan terhadap Citra Perusahaan secara bersama-sama berpengaruh positif dan signifikan terhadap kepuasan nasabah.
\end{abstract}

Kata Kunci : Produk, Kualitas Pelayanan, Citra Perusahaan dan Kepuasan Nasabah.

\begin{abstract}
Every company is trying to get new customers and retain existing customers who already exist, the company's success cannot be separated by their customer satisfaction to the company. The existence of these conditions demand that the company tried to do the measurement of customer satisfaction by analyzing the factors of the product value of the company, the quality of service provided to customers and the company's image in the eyes of customers, so that a company can maintain and even increase the satisfaction of customers.
\end{abstract}

Vol. 2 No.2 Februari 2019 
This study aims to determine the effect of Product, Quality of Service to the Corporate Image and its impact on Customer Satisfaction PT. Bank OCBC NISP, Tbk. Branch Green Garden. The population in this study were all customers of PT. Bank OCBC NISP, Tbk. Branch Green Garden which amounted to 100 people, so this study is a census study.

The analytical tool used in this research is simple regression, multiple linear regression. From the tests there are significant product value, service quality and corporate image together on customer satisfaction showed a statistically significant and positive. This is indicated by the calculated $F$ value of 86251 with $F$ tables is 2,699. The value of $F$ count $>F$ table indicates that the positive impact and significant influence. Thus has been proven that the Products, Corporate Image Quality of Service to jointly positive and significant impact on the Customer Satisfaction.

Keywords: Product, Service Quality, Corporate Image and Customer Satisfaction.

\section{A. Pendahuluan}

Dalam menghadapi persaingan di era global saat ini perusahaan dituntut untuk bekerja lebih efesien dan efektif khususnya dalam nilai produk dan tingkat pelayanan kepada pelanggan. Perusahaan merupakan salah satu organisasi yang menghimpun orang-orang yang biasa disebut karyawan atau pegawai untuk mejalanjan kegiatan rumah tangga produksi perusahaan. Kepuasan pelanggan merupakan unsur terpenting dalam menentukan maju mundurnya suatu perusahaan. Untuk menjaga perusahaan agar tetap eksis dan maju perusahaan harus memenuhi kebutuhan pelanggan agar pelanggan merasa puas dan loyal terhadap perusahaan tersebut.

Bagi masyarakat yang hidup di negara-negara maju, seperti negara Eropa, Amerika dan Jepang, bank sudah bukan merupakan hal yang asng. Bank sudah merupakan mitra dalam rangka memenuhi kebutuhan keuangan mereka. Bank dijadikan sebagai tempat untuk melakukan berbagai transaksi yang berhubungan dengan keuangan seperti, tempat mengamankan uang, melakukan investasi, pengiriman uang, melakukan pembayaran atau melakukan penagihan.

Disamping itu peranan bank sangat memperaruhi kegiatan ekonomi suatu negara. Oleh karena itu kemajuan suatu bank di suatu negara dapat pula dijadikan ukuran kemajuan negara yang bersangkutan. Semakin maju suatu negara, maka semakin besar peranan perbankan dalam mengendalikan negara tersebut. Dalam dunia modern sekarang ini, peranan perbankan dalam memajukan perekonomian suatu negara sangatlah besar. Hampir semua sektor yang berhubungan dengan berbagai kegiatan keuangan selalu membutuhkan jasa bank. Oleh karena itu saat ini dan di masa yang akan datang kita tidak akan lepas dari dunia perbankan, jika hendak menjalankan aktifitas keuangan, baik perorangan maupun lembaga, baik sosial atau perusahaan. 
Secara sederhana bank diartikan sebagai suatu lembaga keuangan yang memiliki kewenangan untuk menghimpun dana dari masyarakat dan menyalurkannya kembali kepada masyarakat dalam bentuk pinjaman modal kerja unuk meningkatkan taraf hidup masyarakat umum.

\section{B. Landasan Teori}

Menurut Buchari Alma (2004:130); Manajemen Pemasaran adalah merencanakan, pengarahan, dan Pengawasan seluruh kegiatan pemasaran perusahaan ataupun bagian di pemasaran.

Pengertian produk (product) menurut Kotler (2009) adalah segala sesuatu yang dapat ditawarkan kepasar untuk mendapatkan perhatian, dibeli, digunakan, atau dikonsumsi yang dapat memuaskan keinginan atau kebutuhan. Secara konseptual produk adalah pemahaman subyektif dari produsen atas sesuatu yang bisa ditawarkan sebagai usaha untuk mencapai tujuan organisasi melalui pemenuhan kebutuhan dan kegiatan konsumen, sesuai dengan kompetensi dan kapasitas organisasi serta daya beli pasar. Sebagian besar pendapatan suatu perusahaan berasal dari produk yang dijualnya kepada konsumen, konsumen akan membeli produk tersebut untuk keperluan sehari-hari, mupun untuk memenuhi kepuasannya.

Kualitas merupakan suatu kondisi dinamis yang berpengaruh dengan produk, jasa, manusia, proses dan lingkungan yang memenuhi atau melebihi harapan (Tjiptono, 2001). Sehingga defenisi kualitas pelayanan dapat diartikan sebagai upaya pemenuhan kebutuhan dan keinginan konsumen serta ketepatan penyampaiannya dalam mengimbangi harapan konsumen (Tjiptono, 2007).

Menurut Kotler (2002:38), citra adalah persepsi masyarakat terhadap perusahaan atau produknya. Sedangkan dalam Buchari Alam (2000:317) mengutip dari pendapat Huddleston (1985:365) mengenai citra adalah kesan yang dipikirkan dan yang diketahui oleh seseorang atau kelompok mengenai suatu hal baik perusahaan maupun produknya yang diperoleh melalui pengalaman.

Berdasarkan definisi diatas dapat disimpulkan bahwa citra perusahaan adalah gambaran singkat mengenai sebuah organisasi atau perusahaan yang diciptakan melalui akumulasi pesan-pesan yanng diterima melalui pengalaman yang dirasakan oleh seluruh indera.

Kepuasan pelanggan adalah perasaan senang atau tidak senang seorang konsumen setelah mengevaluasi kinerja suatu barang atau jasa dengan harapaharapan yang disertakan pada waktu membeli atau menggunakan barang atau jasa tersebut. Menurut Philip Kotler (2002:42), "Kepuasan konsumen adalah perasaan senang atau kecewa seseorang yang berasal dari perbandingan antara kesannya terhadap kinerja (atau hasil) suatu produk dan harapan-harapannya".

\section{Metodologi Penelitian}

Vol. 2 No.2 Februari 2019 
Populasi

Sugiyono (2002:57) memberikan pengertian bahwa:"populasi adalah wilayah generalisasi yang terdiri dari objek atau subjek yang menjadi kuantitas dan karakteristik tertentu yang ditetapkan peneliti untuk dipelajari dan kemudian ditarik kesimpulannya. Riduwan (2002:3) mengatakan bahwa, "populasi adalah keseluruhan dari karakteristik atau unit hasil pengukuran yang menjadi objek penelitian.

Sampel

Arikunto (2006: 131), sampel adalah sebagian atau wakil populasi yang diteliti. Jika kita hanya akan meneliti sebagian dari populasi, maka penelitian tersebut disebut penelitian sampel. Nana Surjana dan Ibrahim (2004:85) menyatakan bahwa sampel adalah sebagian dari populasi terrjangkau ang memiliki sifat sama dengan populasi. Dari kedua pendapat diatas dapat disimpulkan bahwa sampel merupakan sebagian dari jumlah dan karakteristik yang dimiliki oleh populasi. Atau sampel juga dapat disebut sebagai bagian kecil dari anggota populasi yang diambil menurut prosedur tertentu yang dapat mewakili populasinya. Roscoe (1975) dalam Uma Sekaran (1992) memberikan pedoman dalam penentuan jumlah sampel diantara 30 sampai dengan 50 elemen. Jika sampel dipecah lagi ke dalam sub sampel, jumlah minimum sub sampel harus 30 . Untuk menentukan ukuran sampel dapat menggunakan cara slovin.

\section{Hasil dan Pembahasan} Uji Validitas

Tabel 4.1

Pengujian ValiditasInstrumen Pertanyaan Produk $\left(\mathbf{X}_{1}\right)$

\begin{tabular}{|l|l|l|l|}
\hline \multicolumn{1}{|c|}{ No-Quesioner } & r-hitung & $\begin{array}{c}\text { Nilai } \\
\mathbf{r}_{\text {tabel }}\end{array}$ & Kesimpulan \\
\hline $\begin{array}{l}\text { 1. Produk yang disediakan oleh Bank } \\
\text { OCBC NISP telah memberikan } \\
\text { kemudahan dalam aktivitas keuangan } \\
\text { anda }\end{array}$ & 0.800 & 0.1946 & Valid \\
$\begin{array}{l}\text { 2. Produk yang disediakan oleh Bank } \\
\text { OCBC NISP telah memberikan rasa } \\
\text { aman ndan nyaman dalam aktivitas } \\
\text { keuangan anda }\end{array}$ & 0.800 & 0.1946 & Valid \\
\cline { 2 - 4 }
\end{tabular}


3.Jenis produk yang disediakan telah sesuai dengan kebutuhan anda

4. Fitur produk atau jenis produk Bank OCBC NISP telah sesuai dengan keinginan anda

5. Pelayanan yang diberikan oleh Bank telah mendukung aktivitas.

6. Penyediaan produk oleh Bank OCBC NISP sangat membantu dalam kegiatan sehari-hari

\begin{tabular}{|c|c|c|}
\hline 0.744 & 0.1946 & Valid \\
\hline 0.622 & 0.1946 & Valid \\
\hline 0.780 & 0.1946 & Valid \\
\hline 0.901 & 0.1946 & Valid \\
\hline
\end{tabular}

Tabel 4.2

\begin{tabular}{|c|c|c|c|}
\hline No-Quesioner & $\begin{array}{c}r- \\
\text { hituna }\end{array}$ & Nilai & Kesimpulan \\
\hline $\begin{array}{l}1 \text { Petugas Bank OCBC NISP selalu } \\
\text { menepati janji atau kesepakatan yang } \\
\text { telah dbuat dengan anda }\end{array}$ & 0.641 & 0.1946 & Valid \\
\hline $\begin{array}{l}\text { 2Petugas memiliki ketanggapan yang baik } \\
\text { terhadap anda hadapi di Bank OCBC NISP }\end{array}$ & 0.686 & 0.1946 & Valid \\
\hline $\begin{array}{l}\text { 3. Petugas Bank OCBC NISP memiliki } \\
\text { standar keramahan yang sama dari waktu } \\
\text { ke waktu }\end{array}$ & 0.594 & 0.1946 & Valid \\
\hline
\end{tabular}


4. Semua petugas Bank OCBC NISP memiliki respon yang baik terhadap kehadiran anda

5. Petugas selalu mengerti dan paham permasalahan yang anda hadapi saat berada di Bank OCBC NISP

6. Petugas dengan sigap selalu membantu menyelesaikan permasalahan nasabah

\begin{tabular}{|l|l|l|}
\hline 0.817 & 0.1946 & Valid \\
\hline 0.721 & 0.1946 & Valid \\
\hline 0.780 & 0.1946 & Valid \\
\hline
\end{tabular}

Pengujian Valiiditas Instrumen Pertanyaan Kualitas Pelayanan $\left(\mathrm{X}_{2}\right)$

Tabel 4.3

Pengujian Valiiditas Instrumen Pertanyaan Citra Perusahaan(Y)

\begin{tabular}{|l|c|c|c|}
\hline \multicolumn{1}{|c|}{ No-Quesioner } & $\begin{array}{c}\text { r- } \\
\text { hitung }\end{array}$ & $\begin{array}{c}\text { Nilai } \\
\mathbf{r}_{\text {tabel }}\end{array}$ & Kesimpulan \\
\hline $\begin{array}{l}\text { 1. Logo dan identitas atau ciri khas bank } \\
\text { OCBC NISP sangat mudah dikenali }\end{array}$ & 0.813 & 0.1946 & Valid \\
\cline { 2 - 4 } $\begin{array}{l}\text { 2.Anda lebih mudah mengingat Bank OCBC } \\
\text { NISP pada setiap aktivitas keuangan dari } \\
\text { bank lain }\end{array}$ & 0.762 & $\begin{array}{c}0.194 \\
6\end{array}$ & Valid \\
\cline { 2 - 4 } $\begin{array}{l}\text { 3. Anda lebih senang atau lebih terbiasa } \\
\text { menganjurkan teman atau saudara menjadi } \\
\text { pelanggan bank OCBC NISP daripada ke } \\
\text { Bank lain }\end{array}$ & 0.660 & $\begin{array}{c}0.194 \\
6\end{array}$ & Valid \\
\hline $\begin{array}{l}\text { 4. Slogan yang dimiliki Bamk OCBC NISP } \\
\text { telah sesuai dengan pelayanan yang } \\
\text { diberikan }\end{array}$ & 0.728 & $\begin{array}{c}0.194 \\
6\end{array}$ & Valid \\
$\begin{array}{l}\text { 5. Anda selalu merasa aman dalam } \\
\text { bertransaksi dengan Bank OCBC NISP }\end{array}$ & 0.714 & $\begin{array}{c}0.194 \\
6\end{array}$ & Valid \\
\cline { 2 - 5 }
\end{tabular}

Tabel 4.4

Vol. 2 No.2 Februari 2019 
Pengujian Valiiditas Instrumen Pertanyaan Kepuasan Nasabah (Z)

\begin{tabular}{|c|c|c|c|}
\hline No - Quesioner & $\begin{array}{c}r- \\
\text { hitung }\end{array}$ & $\begin{array}{c}\text { Nilai } \\
r_{\text {tabel }}\end{array}$ & $\underset{n}{\text { Kesimpula }}$ \\
\hline $\begin{array}{l}\text { 1. Anda benar-benar merasa puas karena } \\
\text { kebutuhan akan aktivitas keuangan anda telah } \\
\text { disediakan oleh Bank OCBC NISP }\end{array}$ & 0.775 & 0.1946 & Valid \\
\hline $\begin{array}{l}\text { 2. Pelayanan, ketanggapan petugas, dan } \\
\text { keramahan petugas telah sesuai dengan apa } \\
\text { yang anda inginkan }\end{array}$ & 0.571 & 0.1946 & Valid \\
\hline $\begin{array}{l}\text { 3. Petugas dengan senang hati telah } \\
\text { membantu anda dalam mengadakan kegiatan } \\
\text { keuangan di Bank OCBC NISP }\end{array}$ & 0.841 & 0.1946 & Valid \\
\hline $\begin{array}{l}\text { 4. Produk yang disediakan telah sesuai } \\
\text { dengan yang anda harapkan }\end{array}$ & 0.841 & 0.1946 & Valid \\
\hline $\begin{array}{l}\text { 5. Petugas selalu memberikan pelayanan } \\
\text { sesuai dengan yang anda harapkan }\end{array}$ & 0.863 & 0.1946 & Valid \\
\hline $\begin{array}{l}\text { 6. Kecepatan pelayanan yang diberikan } \\
\text { petugas telah sesuai dengan apa yang anda } \\
\text { harapkan }\end{array}$ & 0.516 & 0.1946 & Valid \\
\hline
\end{tabular}

Dari data tabel di atas, semua variabel diperoleh nilai $r$ hitung lebih besar dari 0,1946 atau ( $r_{\text {hitung }}>r_{\text {tabel }}$ ), maka semua item dinyatakan valid. Untuk itu kuesioner yang digunakan layak untuk diolah sebagai data penelitian.

\section{Uji Reliabilitas}

Tabel 4.20 Rekapitulasi Uji Reliabilitas Variabel X1, X2, Y dan Z

\begin{tabular}{|c|c|c|c|c|}
\hline Nomor & Variabel & $\begin{array}{c}\text { Alpha } \\
\text { Cronbach`s }\end{array}$ & $\begin{array}{c}\text { Batas } \\
\text { Minimum }\end{array}$ & Realibilitas \\
\hline
\end{tabular}

Vol. 2 No.2 Februari 2019 


\begin{tabular}{|c|c|c|c|c|}
\hline 1 & X1 & 0,859 & 0,600 & Reliabel \\
\hline 2 & $\mathrm{X} 2$ & 0,791 & 0,600 & Reliabel \\
\hline 3 & $\mathrm{Y}$ & 0,813 & 0,600 & Reliabel \\
\hline 4 & $\mathrm{Z}$ & 0,802 & 0,600 & Reliabel \\
\hline
\end{tabular}

Sumber : Hasil Pengolahan Data

Dari uraian di atas jelas terlihat bahwa semua nilai $r$ dari variabel Produk $\left(X_{1}\right)$, variabel Kualitas Pelayanan $\left(X_{2}\right)$, variabel Citra Perusahaan $(Y)$ dan variabel Kepuasan Nasabah (Z) berada di atas nilai batas minimum yaitu 0,600 sehingga instrument tersebut dinyatakan valid dan reliabel.

Uji Asumsi Klasik

Uji Normalitas Data

\section{Gambar 4.1 Uji Normalitas}

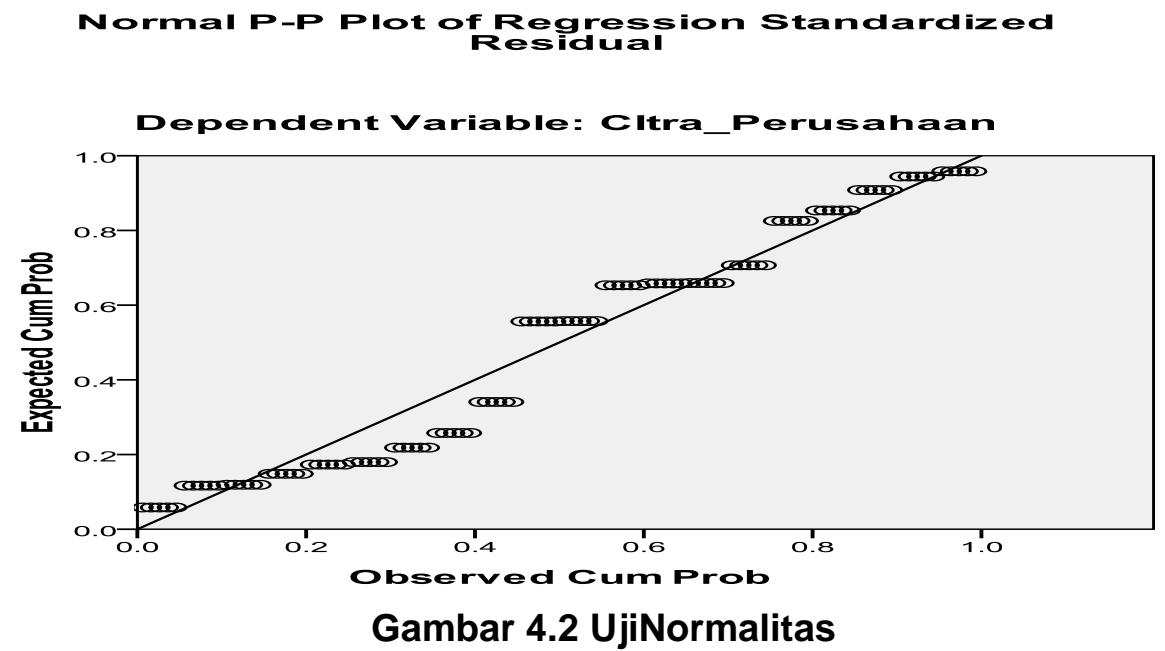

Sumber : Hasil Pengolahan Data dengan SPSS 17.00

Dapat dilihat dari grafik di atas bahwa titik-titik menyebar disekitar garis dan mengikuti garis diagonal, dapat diartikan bahwa nilai residual yang dihasilkan dari regresi tersebut normal.

\section{Uji Multikolinearitas}

Vol. 2 No.2 Februari 2019 
Tabel 4.21 Uji Multikolinieritas variabel Produk, Kualitas Pelayanan

Terhadap Citra Perusahaan

Coefficients $^{\mathrm{a}}$

\begin{tabular}{|c|c|c|c|c|c|c|c|c|}
\hline \multirow[b]{2}{*}{ Model } & & \multicolumn{2}{|c|}{$\begin{array}{l}\text { Unstandardized } \\
\text { Coefficients }\end{array}$} & \multirow{2}{*}{$\begin{array}{c}\text { Stand } \\
\text { ardize } \\
d \\
\text { Coeffi } \\
\text { cients }\end{array}$} & \multirow[b]{2}{*}{$\mathrm{T}$} & \multirow[b]{2}{*}{ Sig. } & \multicolumn{2}{|c|}{$\begin{array}{l}\text { Collinearity } \\
\text { Statistics }\end{array}$} \\
\hline & & B & Std. Error & & & & $\begin{array}{l}\text { Toler } \\
\text { ance }\end{array}$ & VIF \\
\hline \multirow[t]{3}{*}{1} & $\begin{array}{l}\text { (Constan } \\
\text { t) }\end{array}$ & -6.954 & 2.397 & & -2.901 & .005 & & \\
\hline & Produk & .760 & .133 & .517 & 5.716 & .000 & .454 & 2.201 \\
\hline & $\begin{array}{l}\text { Kualitas } \\
\text { Pelayana } \\
\text { n }\end{array}$ & .498 & .133 & .339 & 3.748 & .000 & .454 & 2.201 \\
\hline
\end{tabular}

a. Dependent Variable: Citra_Perusahaan

Sumber : Hasil Pengolahan Data

Dari Tabel 4.21di ketahui bahwa :

1. Nilai tolerance variabel Produk $0.454>0.10$ dan nilai VIF variabel Produk2.201<10.

2. Nilai tolerance variabel Kualitas Pelayanan $0.454>0.10$ dan nilai VIF variabel Kualitas Pelayanan2.201< 10

3. Maka dapat disimpulkan tidak terjadi multikolinearitas antar variabel independent dalam model regresi karena nilai tolerance semua variabel $>0,1$ dan nilai semua variabel VIF $<10$

Uji Autokorelasi 
Model regresi yang baik mensyaratkan tidak adanya masalah autokorelasi yaitu varian sampel tidak dapat menggambarkan varian populasinya dan untuk mendeteksi ada tidaknya autokorelasi.

Uji autokorelasi bertujuan untuk menguji apakah dalam suatu model regresi linier ada korelasi antara kesalahan pengganggu pada periode $t$ dengan kesalahan pada periode t-1 atau sebelumnya. Autokorelasi muncul karena observasi yang berurutan sepanjang waktu berkaitan satu sama lain.

Menurut Gujarati (2003:215) untuk memeriksa adanya autokorelasi, biasanya dilakukan uji statistik Durbin-Watson (DW). Kriteria uji korelasi dari variabel produk dan harga terhadap kepuasan pelanggan adalah sebagai berikut:

$\mathrm{Ha}$ : Terjadi Autokorelasi

Ho : Tidak terjadi autokorelasi

Nilai statistik hitung diatas dibandingkan dengan nilai teoritisnya,dan kriteria pengambilan kesimpulannya sebagai berikut:

Jika $\mathrm{DW}<\mathrm{dL}$ atau $\mathrm{DW}>4-\mathrm{dL}$, maka terdapat autokorelasi

Jika dU $<\mathrm{DW}<4-\mathrm{dU}$, maka tidak terdapat autokorelasi

Jika $\mathrm{dL}<=\mathrm{DW}<=\mathrm{dU}$ atau $4-\mathrm{dU}<=\mathrm{DW}<=4-\mathrm{dL}$, uji Durbin Watson tidak menghasilkan kesimpulan yang pasti (inconclusive).

Adapun kriteria pedoman Uji Durbin Watson yang menjadi acuannya adalah sebagai berikut:

Tabel 4.10

Pedoman Interpretasi Uji Durbin-Watson

\begin{tabular}{|c|c|}
\hline Kriteria & Keterangan \\
\hline$<1$ & Ada autokorelasi \\
\hline $1,1-1,54$ & Tanpa kesimpulan \\
\hline $1,55-2,46$ & Tidak ada autokorelasi \\
\hline $2,46-2,9$ & Tanpa kesimpulan \\
\hline$>2,9$ & Ada autokorelasi \\
\hline
\end{tabular}

Sumber : Sugiyono (2012:184)

Vol. 2 No.2 Februari 2019 
Berdasarkan hasil analisa dengan program SPSS 17.00 maka diperoleh hasil uji autokorelasi antara produk dan kualitas pelayanan terhadap citra perusahaan sebagai berikut:

Tabel 4.22

Model Summary

\begin{tabular}{|l|r|r|r|r|r|}
\hline Model & $\mathrm{R}$ & $\begin{array}{c}\mathrm{R} \\
\text { Square }\end{array}$ & $\begin{array}{c}\text { Adjusted R } \\
\text { Square }\end{array}$ & $\begin{array}{c}\text { Std. Error of } \\
\text { the Estimate }\end{array}$ & $\begin{array}{c}\text { Durbin- } \\
\text { Watson }\end{array}$ \\
\hline 1 & $.800^{\mathrm{a}}$ & .640 & .633 & 1.890 & 2.422 \\
\hline
\end{tabular}

a. Predictors: (Constant), Kualitas_Pelayanan, Produk

b. Dependent Variable: Citra_Perusahaan

Dari tabel 4.22 di atas, diperoleh nilai Durbin-Watson sebesar 2.422 yang berarti berada diantara $(1,550$ - 2,460), dengan demikian model regresi ini tidak ada autokorelasi.

\section{Uji Heteroskedastisitas}

tolq19tssว

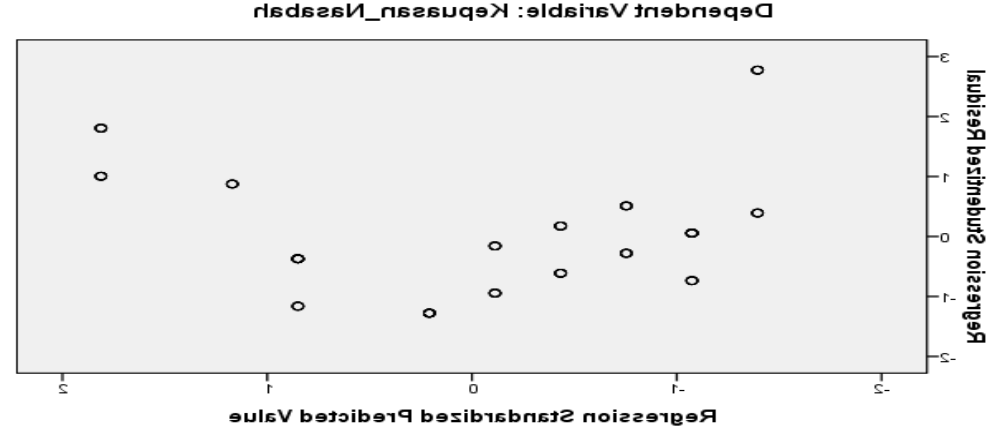

Data Primer, tahun 2016, diolah dengan SPSS Versi 17.00

Vol. 2 No.2 Februari 2019 


\section{Gambar 4.9}

\section{Hasil Uji Heteroskedastisitas}

Berdasarkan hasil gambar di atas, dapat dilihat bahwa titik-titik pada grafik scatterplot tidakmempunyai pola penyebaran yang jelas atau tidak membentuk pola-pola tertentu dan titik-titik tersebut menyebar di atas dandibawah angka 0 pada sumbu $\mathrm{Y}$, dengan demikian hal ini menunjukkan bahwa tidak terdapat gangguanheteroskedastisitas pada model regresisehingga model regresi ini layak dipakai.

\section{Kesimpulan}

Berdasarkan hasil penelitian pada responden nasabah Bank OCBC NISP ini, maka dapat disimpulkan beberapa hal sebagai berikut ini :

Berdasarkan latar belakang masalah dan pembatasan masalah pada penelitian ini dapat dirumuskan permasalahan penelitian sebagai berikut :

\section{Produk $\left(\mathrm{X}_{1}\right)$ Terhadap Citra Perusahaan (Y)}

Pada hasil pengujian hipotesis secara parsial produk terhadap citra perusahaan diperoleh nilai t hitung sebesar 5.716 lebih besar dari nilai t tabel 0,1985 atau $(5.716>0,1985)$. Dengan demikian $\mathrm{H}_{\circ}$ ditolak dan $\mathrm{H}_{1}$ diterima artinya terdapat pengaruh yang signifikan antara Produk $\left(X_{1}\right)$ terhadap Citra Perusahaan $(Y)$ Hal ini menunjukkan bahwa semakin tepat produk yang diberikan maka citra perusahan Bank OCBC NISP akan semakin meningkat dan semakin dikenal oleh masyarakat.

2. Kualitas Pelayanan $\left(\mathrm{X}_{2}\right)$ Terhadap Citra Perusahaan ( $\mathrm{Y}$ )

Pada hasil pengujian hipotesis secara parsial kualitas pelayanan terhadap citra perusahaan diperoleh nilai t hitung sebesar 3.748 lebih besar dari nilai t tabel 0,1985 atau (3.748>0,199). Dengan demikian $\mathrm{H}_{0}$ ditolak dan $\mathrm{H}_{1}$ diterima artinya terdapat pengaruh yang signifikan antara Persepsi kualitas pelayanan $\left(\mathrm{X}_{2}\right)$ terhadap citra perusahaan $(\mathrm{Y})$. Hal ini menunjukkan bahwa semakin baik pelayanan yang diberikan kepada nasabah, maka citra Bank OCBC NISP akan semakin meningkat dan lebih dikenal oleh masyarakat.

3. Produk $\left(X_{1}\right)$ dan Kualitas Pelayanan $\left(X_{2}\right)$ Terhadap Citra Perusahaan $(Y)$ Pada hasil pengujian hipotesis secara simultan produk dan kualitas pelayanan terhadap citra pelanggan diperoleh nilai $F$ hitung lebih besar nilai $F$ tabel atau (86.251 > 2,699). Dengan demikian $\mathrm{H}_{\circ}$ ditolak dan $\mathrm{H}_{1}$ diterima artinya terdapat pengaruh yang signifikan antara Produk $\left(X_{1}\right)$, Kualitas pelayanan $\left(X_{2}\right)$ terhadap Citra perusahaan $(Y)$ secara simultan. Hal ini menunjukkan bahwa semakin tepat produk yang diberikan dan semakin baik kualitas pelayanan yang diberikan maka citra Bank OCBC NISP akan semakin meningkat dan semakin dikenal oleh masyarakat.

\section{Citra Perusahaan (Y) terhadap Kepuasan Nasabah (Z)}


Pada hasil pengujian hipotesis secara parsial citra perusahaan terhadap kepuasan nasabah diperoleh nilai koefisien korelasi antara variabel Citra Perusahaan ( $Y$ ) dengan Kepuasan Nasabah (Z) adalah sebesar 0,720 memiliki hubungan yang positif (karena hasilnya positif), korelasi antar dua variabel bersifat signifikan karena nilai signifikansi (2-tailed) sebesar 0,000 lebih kecil dari sig $\alpha$. 0,05 atau $(0,000<0,05)$. Sedangkan nilai pengaruhnya hanya sebesar $(0,720)^{2} \times 100 \%=0,519$. Jadi pengaruh Citra Perusahaan $(Y)$ terhadap kepuasan Nasabah (Z) sebesar $51.90 \%$ sedangkan sisanya (100\% $-51,90 \%=48,10 \%$ ) sebesar $48,10 \%$ dipengaruhi faktor lain.

\section{Saran}

1. Pihak manajemen PT Bank OCBC NISP, Tbk agar lebih meningkatkan citra perusahaan dalam hal ini memperhatikan aspek produk agar nasabah dapat memperoleh produk-produk yang memiliki fitur dan jenis produk yang sesuai dengan keinginan nasabah. Dengan cara demikian maka citra perusahaan Bank OCBC NISP akan meningkat.

2. Pihak manajemen PT Bank OCBC NISP, Tbk agar lebih meningkatkan citra perusahaan dalam hal ini memperhatikan aspek kualitas pelayanan dimana petugas belum memiliki ketanggapan yang baik dalam melayani nasabah, oleh karena itu pihak manajemen agar dapat melakukan coaching dan training kepada petugas khususnya frontliner agar nasabah dapat merasa puas dan menaikan citra perusahaan Bank OCBC NISP.

3. Pihak manajemen Bank OCBC NISP harus melakukan usaha-usaha agar lebih meningkatkan kepuasan nasabah yaitu dengan memperhatikan aspek citra perusahaan dimana nasabah belum mudah mengingat Bank OCBC NISP pada setiap aktivitas keuangan dari bank lain. Oleh karena itu pihak manajemen agar melakukan promosi di media cetak atau media elektronik agar nasabah dapat terus mengingat Bank OCBC NISP dan menjadi branch image nasabah di setiap aktivitas keuangan.

4. Perlu dilakukan penelitian lanjutan terhadap variabel-variabel bebas selain produk, kualitas pelayanan dan cita perusahaan yang mempunyai hubungan atau yang dapat mempengaruhi kepuasan nasabah.

\section{E. DAFTAR PUSTAKA}

Amirullah, 2015, Pengantar Manajemen, Mitra Wacana Media, Bekasi.

Duwi Priyatno, 2014, SPSS 22 Pengolah Data Terpraktis, Andi Offset, Yogyakarta. 
Etta Mamang Sangadji dan Sopiah, 2013, Prilaku Konsumen Disertai Himpunan Jurnal Penelitian, Andi Offset, Yogyakarta.

Freddy Rangkuti, 2013, Customer Service Satisfaction dan Call Center Berdasarkan ISO 9001, Gramedia, Jakarta.

Freddy Rangkuti, 2015, Riset Pemasaran, Gramedia, Jakarta.

Juli Irmayanto dkk, 2004, Bank dan Lembaga Keuangan, Universitas Trisakti, Jakarta.

J. Supranto, 2011, Pengukuran Tingkat Kepuasan Pelanggan, Rineka Cipta, Jakarta.

Kasmir, 2002, Dasar-Dasar Perbankan, Raja Grafindo Persada, Jakarta.

Kasmir, 2014, Bank dan Lembaga Keuangan Lainnya, Raja Grafindo Persada, Jakarta.

Philip Kotler and Kevin Lane Keller, 2009, Manajemen Pemasaran, PT Macanan Jaya Cemerlang, Klaten.

M. Manullang, 2012, Dasar-Dasar Manajemen, Gadjah Mada University Press, Yogyakarta.

Riduwan, 2010, Metode dan Teknik Menyusun Tesis, Alfabeta, Bandung.

Syamsir Torang, 2014, Organisasi dan Manajemen, Alfabeta, Bandung.

Wibowo, 2015, Perilaku Dalam Organisasi, Rajagrafindo Persada, Jakarta.

V. Wiratna Sujarweni, 2014, Metodologi Penelitian, Pustakabarupress, Yogyakarta. 